\title{
Laptop energy-saving opportunities based on user behaviors
}

\author{
Morris E. Jones Jr.• Belle W. Y. Wei • \\ Donald L. Hung
}

Received: 25 August 2011 /Accepted: 23 July 2012 /Published online: 14 August 2012

(C) The Author(s) 2012. This article is published with open access at Springerlink.com

\begin{abstract}
In order to improve the energy efficiency of laptop use and design, it is important to gain knowledge of how laptops are being used in real-world settings. However, the current workload studies have focused on computer-usage patterns of business users, but not those of consumer users. As part of the $u$ ! Green project at ABC University, a pilot study was undertaken to develop and test software tools and methods for monitoring the laptop computer usage of 13 college students for a period of 1 month. This paper describes such tools and methods for monitoring and collecting laptop usage data. It also illustrates how the collected data can be analyzed to obtain high-impact energy usage patterns, which include long idle periods, excessive use of the AC power source, and high backlight levels. These identified high-impact usage patterns, if confirmed by our subsequent study, offer valuable user behavioral insights to advance more energy-efficient laptop use and design.
\end{abstract}

M. E. Jones Jr. • D. L. Hung

College of Engineering, San José State University,

One Washington Square,

San Jose, CA 95192, USA

M. E. Jones Jr.

e-mail: morris.jones@sjsu.edu

D. L. Hung

e-mail: donald.hung@sjsu.edu

B. W. Y. Wei $(\bowtie)$

Academic Affairs Division, Chico State University,

Kendall Hall 106,

Chico, CA 95929, USA

e-mail: bwwei@csuchico.edu
Keywords Laptop energy efficiency · Laptop usage data Computer usage monitoring $\cdot$ Computer usage data $\cdot$ Laptop user behaviors

\section{Introduction}

The energy consumption of consumer electronics has skyrocketed. According to the International Energy Agency (2009), it will triple over the next two decades, reaching a level equivalent to the present total home electricity consumption of the U.S. and Japan combined. For example, the installed base of PCs reached 1.4 billion in 2010 (Vasquez and Shiffler 2011) and laptops account for more than $40 \%$ of personal computers sold in America (Kahn 2010). It is critical to improve the energy efficiency of these devices. The $\mathrm{u}$ !Green project at $\mathrm{ABC}$ University (ABC) aims to improve the energy efficiency of laptop usage and design informed by better understanding of user behaviors (especially those of consumers), as user behaviors play an important role in the total laptop system power consumption (Mahesri and Vardhan 2005).

As for user behaviors, those of business users, not consumer users, have been studied extensively (Moorefield et al. 2011; Mercier and Moorefield 2011). In cases in which household energy consumption is studied, the focus is on the plug level (Porter et al. 2006), not the device level. For the few energyefficiency benchmarks available (Energy Star 2009; MobileMark 2007; Rivoire et al. 2007), simple 
workloads are assumed, failing to reflect the complexity and variety of user behaviors. As a result, the $u$ ! Green project needs to first study how consumers use their laptops in real-world settings.

Among the plethora of laptop users, we have chosen college students as the initial target group as $88 \%$ of them possess a laptop (Smith et al. 2009). We began with a pilot study with a group of $13 \mathrm{ABC}$ students. Its goal was to develop and test software tools and methods that are used for monitoring, collecting, processing, and analyzing real-world laptop usage data. In summer 2010, we beta tested the tools on these 13 students' laptops for 1 month. The tools developed and methods used are presented in this paper. Also presented is the analysis of preliminary results.

The rest of the paper is organized as follows. The second section presents an overview of current laptop power management technologies, providing a context for interpreting collected usage data. The third section describes the methods used and the monitor software developed for this pilot project. The fourth section presents examples of the analysis of collected data with a focus on those contributing to the most energy inefficiency. The fifth section summarizes our findings and discusses how to refine the pilot study's methods and tools for the full-scale study with $100 \mathrm{ABC}$ students for a 3-month period.

\section{Power management technologies}

Over the years, the PC industry has developed energy-saving strategies for components and major computer subsystems with the objective of extending the battery life (Gain 2005). Examples include voltage and frequency scaling for the CPU, reduced brightness for the backlight, turning off the disk drive when not needed (Yung-Hsiang and De Micheli 2001), and disabling some system components while in battery mode (Intel 2010). These energy-savings mechanisms can be accessed by the operating system via the Advanced Configuration and Power Interface, and the operating system's power management tools permit users to select trade-offs between machine characteristics and battery life (Microsoft 2009). However, most users do not take advantage of the power management features on their PCs (Webber et al. 2005). Further, as the design focus is on extending battery life, not on minimizing overall energy consumption, the laptop typically operates in a high-energy mode while on AC power, thereby forgoing the energysavings opportunities offered by the laptop.

\section{Methods for collecting laptop usage data}

To obtain laptop usage data in real-world settings, a software monitor tool written in $\mathrm{C}++$ was developed for Windows 7, Windows Vista, and Windows XP. It runs in the background of the user's laptop without user interface. The software monitor initiates a data collection process after a 5 -s pause, and the collection process takes 2 to $5 \mathrm{~s}$ to complete (due to system call scheduling). The data collection period is thus between 7 and $10 \mathrm{~s}$. It is noted that the monitor stops when the machine is in the sleep, hibernate, or shutdown mode (Microsoft 2011). As a result, there are no data collected during those times. Since the monitor collects information about shutdown events, we know when the laptop was turned off and when it entered sleep/hibernate. Across the 13 laptops, machines were collecting data for $20 \%$ of the time, in sleep/hibernate for $41 \%$ of the time, and in shutdown mode for $39 \%$ of the time.

When data collection takes place, the software monitor tool uses system calls extensively to gather the laptop's system and usage information, which includes the following:

- CPU characteristics (voltage, speed, number of physical/logical cores),

- power source (AC mains or battery),

- battery (capacity),

- display backlight levels (brightness in both AC and DC mode),

- CPU utilization,

- time of the last user input (mouse, keyboard, joystick, etc.),

- wired and wireless network interfaces and cumulative traffic (in bytes and packets), and

- time of shutdown events.

In addition, information on visible processes, processes that are visible by the monitor tool, and their related resource consumption was collected. This includes process creation time, execution time, disk $\mathrm{read} / \mathrm{write}$ rates, system resources used, and the names of all .exe and .dll files loaded. 


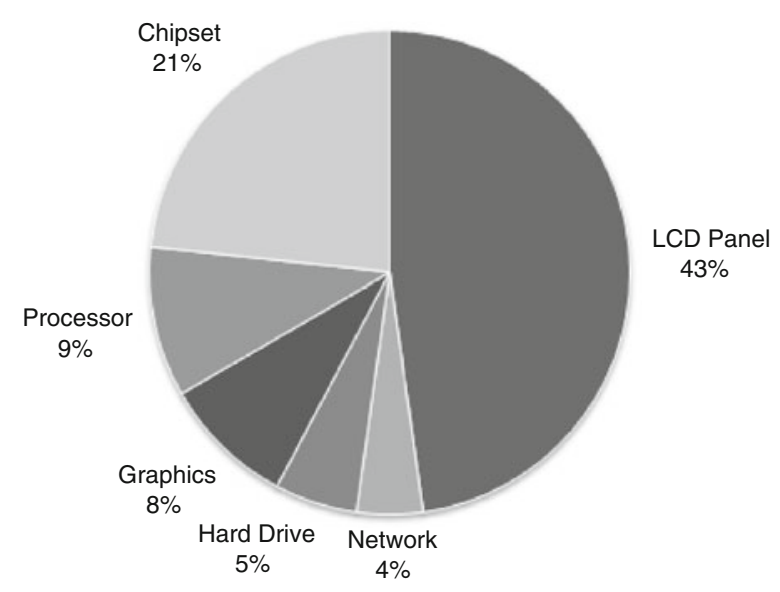

Fig. 1 Industry laptop power budget by category (Sinofsky 2009)

Altogether, the monitor software collected a total of approximately 3 GB of raw data from 13 participants' laptop computers during the 1-month testing period. The data include about one million sample points. That is, data were collected for the 13 laptops for approximately $2,260 \mathrm{~h}$ during this 1 -month period. Data were collected for each laptop for, on average, $170 \mathrm{~h}$ in total and about $6 \mathrm{~h}$ each day.

\section{Examples of data analysis}

The collected data were saved as XML files on the user disks. To reduce the storage requirements on the user laptop, the data were stored as the differences from the values of the previous sample with the first sample storing full values. At the end of the study period, the XML files were transferred from participants' laptops to a server, followed by a reconstruction of full sample data. The full sample data were then written into a SQL database for preprocessing, which includes converting the sample data to suitable formats and extracting information for data analysis.

Along with developing the monitor tool and collecting laptop usage data, we also conducted physical power measurements on laptops in the laboratory. Lab measurements validate industry literature showing the relative power consumption of various components in a laptop computer system, such as backlight, graphics, CPU, and system support items (see Fig. 1).

The data in Fig. 1 show that the LCD display contributes $43 \%$ of the total laptop power budget, whereas the processor contributes $9 \%$, pointing out the areas in which significant energy savings can be realized. These include the laptop operation state (off, sleep, hibernate, or active), the power mode and corresponding power management profiles, and brightness levels of backlight displays.

Input intervals

As described in the third section, the software monitor collects laptop information every 7 to $10 \mathrm{~s}$. During each sample period, the time of the last user input (keyboard, mouse, etc.) was recorded. (This information is used by the operating system for screen blanking and other power management decisions.) If more than one input event occurred during a sample period, only the time for the last one was recorded. The interval between the times of two consecutive user inputs can thus be calculated, and referred to as input interval. Altogether, there are 461,572 input intervals.
Fig. 2 Distribution of input intervals

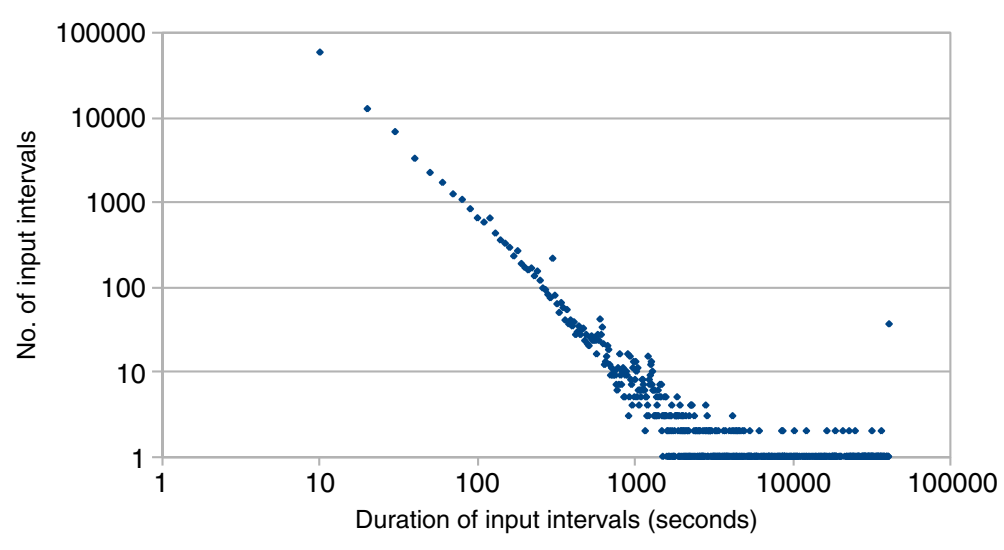


Fig. 3 Battery capacity levels by sample count

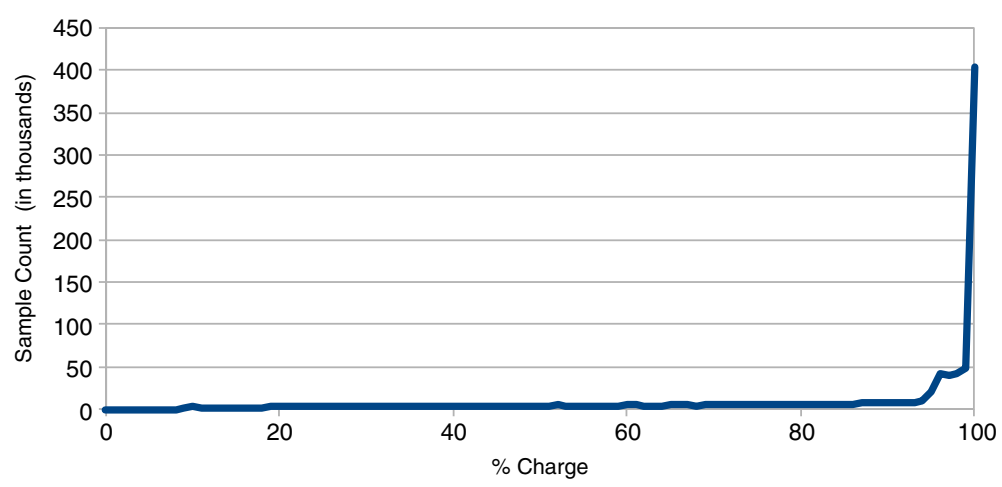

A distribution of these input intervals is presented on a $\log -\log$ graph in Fig. 2, in which the input intervals are counted in bins of $10 \mathrm{~s}$ each. There are 4,096 bins; all input intervals longer than 40,950 s $(\sim 11.4 \mathrm{~h})$ are placed in a single bin. It is noted that $28 \%$ of samples have input intervals of $5 \mathrm{~min}$ or longer.

While the number of long input intervals is modest, they are significant due to their long duration. In Fig. 2, there are about 400 intervals longer than an hour. Since the data were collected from 13 users over a 1-month period and the data collection stopped when the machine was not running, Fig. 2 indicates that on average, each user stopped providing input for at least an hour each day of the study period. During idle periods longer than $5 \mathrm{~min}$, the top resourceconsuming processes were mostly browsers, virus scanners, and the windows display manager. It is noted that during these long idle periods, the machines entered neither sleep nor hibernate mode, implying that power management features were disabled. An informal survey of our participants revealed that most of them had disabled screen savers and other power management features for the ease of watching video. They apparently had not enabled the power management features after disabling them. Christensen et al. (2004) also found that users disabled their power management features to ensure access to their computers at all times.

These data suggest that long idle periods present opportunities for power savings. Our reference machine, the HP ProBook 4310a (Intel Core 2-Duo T6400@2.00 GHz processor, LED backlight, Windows 7), consumes $15 \mathrm{~W}$ on average. Given that approximately $8 \%$ of the participants' idle input intervals were $5 \mathrm{~min}$ or longer, each participant would have saved up to $200 \mathrm{Wh}$ during the 1-month study period if they had enabled power-saving states (sleep, hibernate, or shutdown) at the 5-min idle time. Assuming a 550 million installed laptop base worldwide (Kahn 2010; Vasquez and Shiffler 2011) and a potential worldwide energy consumption of $17 \mathrm{TWh}$, enabling power-saving states could result in a savings of up to $1.3 \mathrm{TWh}$ per year.

Power source and battery usage

The power source (AC mains or battery) and battery capacity levels were collected at each sample point. The samples were analyzed to gain insight into how
Fig. 4 Samples by backlight percentage

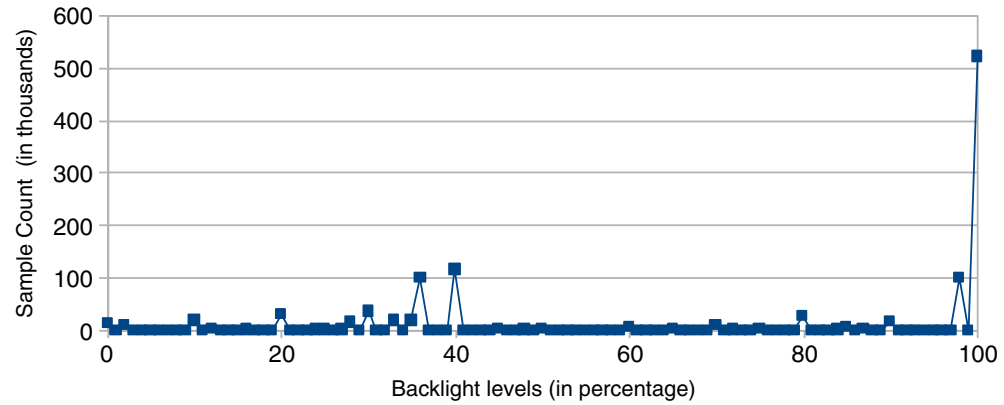


the participants powered their machines. The first analysis was a sample count of AC and battery operations. Among the 1,067,539 samples, $57 \%$ of them had AC as their power source, and $43 \%$ had battery.

Figure 3 shows the distribution of samples, running at each battery capacity level when in the battery mode. The bulk of the samples are at a battery level at or above $95 \%$. These data suggest that users are utilizing the battery mode for short intervals, presumably to move from one power outlet to another.

To recharge the battery, AC operations are needed until the battery is fully charged. An analysis showed that $46 \%$ of the AC-mode samples had the $100 \%$ battery capacity level. That is, for $26 \%(0.46 \times 0.57)$ of the time, the $\mathrm{AC}$ operations might not have been necessary. This is significant when one considers the difference in energy consumption between $\mathrm{AC}$ and battery modes for laptops. For instance, our laboratory power measurement showed that our reference laptop system, HP ProBook 4310a, used $20 \%$ more energy for $\mathrm{AC}$ while running a 40-min DVD video. This difference is attributed to the setting of the laptop's power management profile to lower power while on battery. If these machines had been returned to battery operation, then each user could have saved $136 \mathrm{Wh}$ during the month. This translates to an annual savings of $800 \mathrm{GWh}$ per year for all installed laptops.

\section{Backlight levels}

For each sample, the backlight levels were recorded in percentage of full brightness. Its histogram is shown in Fig. 4 in which $63 \%$ of the samples operated at $90 \%$ or higher backlight levels and $52 \%$ of the samples at $100 \%$. If the $100 \%$ backlight levels were turned down to lower levels as shown in Table 1, then the following amounts of energy could be saved assuming a 4.5 -W backlight (measured on the reference laptop).

Table 1 Potential worldwide energy savings from lower backlight levels

\begin{tabular}{lll}
$\begin{array}{l}\text { Backlight level } \\
(\%)\end{array}$ & $\begin{array}{l}\text { Savings/user/month } \\
(\mathrm{Wh})\end{array}$ & $\begin{array}{l}\text { Worldwide savings/year } \\
(\mathrm{GWh})\end{array}$ \\
\hline 80 & 34 & 230 \\
60 & 69 & 450 \\
40 & 103 & 680
\end{tabular}

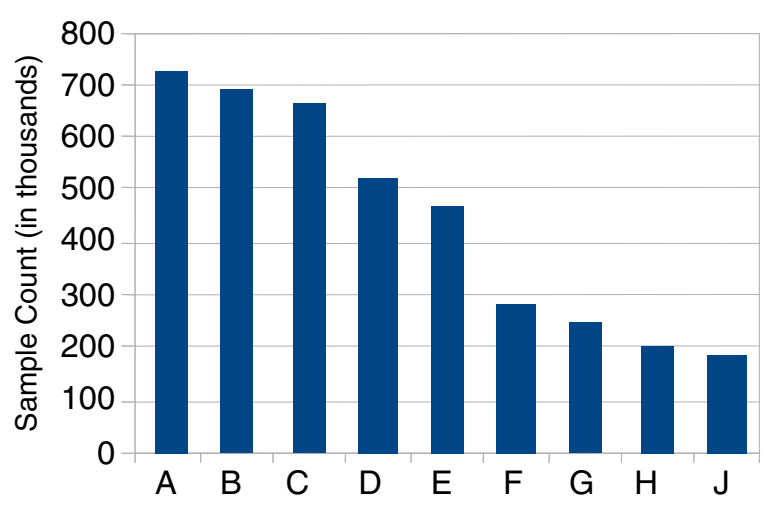

Fig. 5 Top nine processes by sample count

A quick sample test indicated that many users could not tell the backlight had been reduced to the $80 \%$ level when asked if the backlight level was acceptable. The typical backlight setup has higher levels on AC than battery. Whereas this setup extends battery life, it causes higher energy consumption for AC.

\section{Processes}

The information on user-visible processes was collected for each sample. Figure 5 shows the sample counts for the top nine user-visible processes (out of 832 different application processes), which account for nearly $80 \%$ of the total process samples. Each sample had, on average, ten user-visible processes. In Fig. 5, actual process names are replaced with letters and their functions are identified in Table 2. From Table 2, one can see that only four out of nine top visible processes are user-controllable applications, which are browser applications.

Table 2 Top nine sample processes

\begin{tabular}{lll}
\hline Name & User/OS & Description \\
\hline A & OS & Display manager \\
B & User & Web browser \\
C & OS & User shell \\
D & User & Web browser \\
E & User & Web browser \\
F & User & Second browser helper process. \\
& & (Runs media typically) \\
G & OS & User shell application \\
H & OS & Laptop touch pad interface \\
J & OS & Dynamic linking support \\
\hline
\end{tabular}


Fig. 6 Distribution of active browser applications

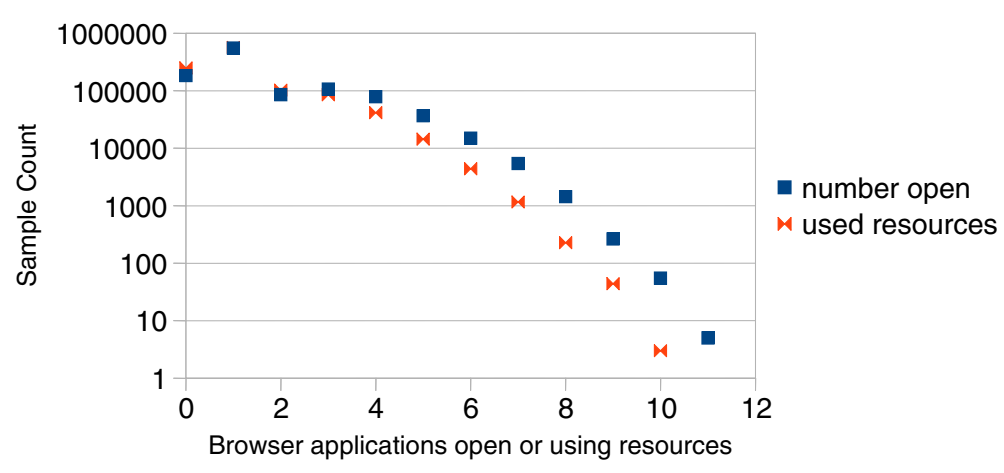

Not all user-visible (or open) browser applications are active, i.e., consuming computer resources. Figure 6 presents the distribution of samples for both active and open browser applications. The maximum number of open browser applications was 11 , the average 1.9 , and the median 4 . As for active browser applications, $50 \%$ of all samples had a single active browser application; $23 \%$ had two or more active browsers applications; about $2 \%$ had five or more active browser applications. A quick lab investigation shows that browser advertisement plugins are programmed to run even when the browser is minimized. This may account for multiple active browser applications observed.

While there are a large number of active browser applications, their impact on possible energy savings might be limited, given the relatively low power consumption of the CPU among various components of a laptop (see Fig. 1) and the low CPU utilization levels, which are shown in Fig. 7. The median CPU utilization level is about $23 \%$. Measuring the power of active browser applications in the laboratory was challenging due to the burst nature of laptop power consumption.

\section{Conclusion and further study}

The small sample size of the pilot study precludes us from drawing a definitive conclusion on the laptop usage patterns by college laptop users. However, it points out areas on which to focus in the full-scale study. In particular, it revealed high-impact energy usage patterns that, if changed, could lead to significant energy savings. These include: machines left running with no user input for extended periods of time; higher energy-consuming $\mathrm{AC}$ operations used even when the battery is $100 \%$ charged; backlight levels remaining high much of the time. These findings, if verified, suggest three high-impact energysaving opportunities: switching between AC and battery mode, controlling backlight levels, and optimizing power management settings. Additional research might reveal savings within the area of active browser processes and browser advertisement plugins.

Furthermore, the pilot study has allowed us to test our software tools and sharpened the focus of our data collection and analyses for subsequent studies. In the pilot study, we collected much data (i.e., about 230 Mbytes per user) without knowing which items would be
Fig. 7 Levels of CPU utilization

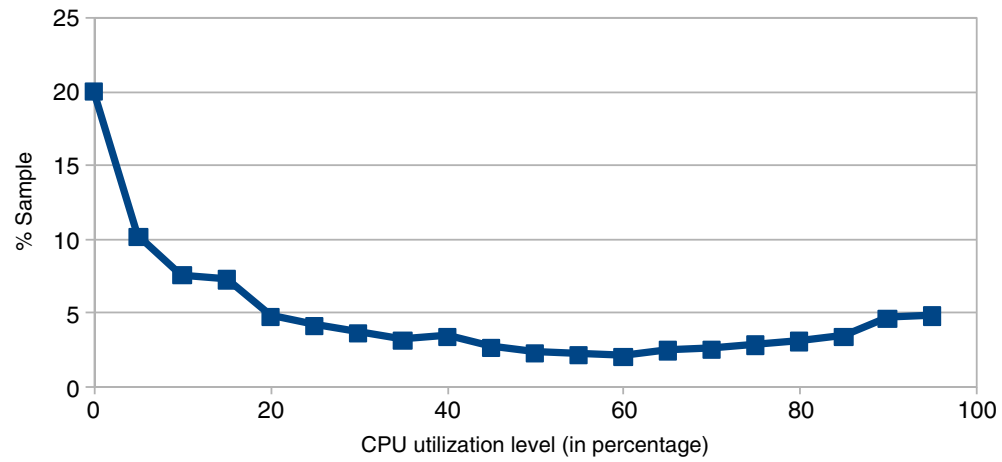


significant with respect to energy savings. However, the results of our pilot study reveal which data can be eliminated in subsequent studies. For example, detailed network information will not be collected because we found little correlation between network data and resources consumed. This might have been complicated by a large number of browser applications open at any one time. Another example is that we will extend the collection period to $1 \mathrm{~min}$ from 5 to $7 \mathrm{~s}$. Little was gained from examining finer sample resolutions.

The next phase of the project is to expand to a study group of 100 students for a period of 3 months with tools and methods developed and refined as the result of the pilot study. The data from the full-scale study will verify and possibly expand the areas of energy-saving opportunities described above. These valuable usage data will not only aid industry to build more energyefficient laptops, but also educate college students on adopting more energy-efficient use of their laptops.

Acknowledgments The authors would like to thank graduate students Jay Patel, Pankaj Sitpure, and Namrata Buddhadev, for their assistance in the data collection and analysis of this pilot study. We also want to thank Katherine Casey for her assistance in recruiting and working with the student volunteers.

Open Access This article is distributed under the terms of the Creative Commons Attribution License which permits any use, distribution, and reproduction in any medium, provided the original author(s) and the source are credited.

\section{References}

Christensen, K. J., Gunaratne, C., Nordman, B., \& George, A. D. (2004). The next frontier for communications networks: power management. Computer Communications, 27, $1758-1770$.

Energy Star. (2009). Program requirements for computers: Version 5.0. http://www.energystar.gov/ia/partners/prod development/revisions/downloads/computer/Version5.0_ Computer_Spec.pdf. Accessed 5 December 2011.

Gain, B. (2005). The notebook battery-life kings. Processor, 27 (6), 1-8.

Intel Corporation. (2010, August). Intel power management technologies for processor graphics, display, and memory: White paper for 2010-2011 desktop and notebook platforms. http://www.intel.com/Assets/PDF/whitepaper/ 324226.pdf. Accessed 6 December 2011.

International Energy Agency. (2009). Gadgets and gigawatts: Policies for energy efficient electronics. http://www.iea.org/ textbase/nppdf/free/2009/gigawatts2009.pdf. Accessed 15 August 2011.

Kahn, E. (2010, July 26). Forrester Research ereader forecast, 2010 To 2015 (US). http://www.forrester.com/rb/Research/ research_ereader_forecast,_2010_to_2015_us/q/id/57199/ t/2. Accessed 5 December 2011.

Mahesri, A., \& Vardhan, V. (2005). Power consumption breakdown on a modern laptop. In B. Falsafi \& T. N. Vijaykumar (Eds.), Power-aware computer systems (pp. 165-180). Berlin: Springer.

Mercier, C., \& Moorefield, L. (2011, July). Commercial office plug load savings and assessment: Final report. http:// www.efficientproducts.org/reports/plugload/Ecova Office $\% 20$ Plug $\% 20$ Load $\% 20$ Assessment_Final $\%$ 20Report\%20Nov\%202011.pdf. Accessed 10 December 2011.

Microsoft Corporation. (2009, April 30). Power Management in Windows 7 Overview. http://www.microsoft.com/ download/en/details.aspx?displaylang=en $\& i d=23878$. Accessed 6 December 2011.

Microsoft Corporation. (2011). Turn off a computer: frequently asked questions. http://windows.microsoft.com/en-US/ windows-vista/Turn-off-a-computer-frequently-askedquestions. Accessed 5 December 2011.

MobileMark. (2007). Trade literature of Business Applications Performance Corporation (BAPCo).

Moorefield, L., Frazer, B. \& Bendt, P. (2011, April). Office plug load field monitoring report. http://www.energy.ca.gov/ 2011publications/CEC-500-2011-010/CEC-500-2011010.pdf. Accessed 15 November 2011.

Porter, S. F., Moorefield, L., \& May-Ostendorp, P. (2006, October 31). Final field research report. http://www.efficientproducts.org/documents/Plug_Loads_CA_Field_Research_Report_Ecos_2006.pdf. Accessed 8 December 2011.

Rivoire $\bar{S}$., Shah M. A., Ranganathan, P., \&Kozyrakis, C. (2007). JouleSort: A balanced energy-efficiency benchmark. Proceedings of ACM SIGMOD'07, June 12-14, 2007, Beijing, China.

Sinofsky, S. (2009, January 6). Windows 7 Energy efficiency. http://blogs.msdn.com/b/e7/archive/2009/01/06/ windows-7-energy-efficiency.aspx. Accessed 28 November 2011.

Smith, S. D., Salaway, G., \& Caruso, J. B. (2009). The ECAR Study of undergraduate students and information technology, 2009. Educause

Vasquez, R. \& Shiffler, G., (2011, March 24). Forecast: PC installed base, worldwide, 2006-2015. http://www.gartner.com/DisplayDocument?id=1602818. Accessed 3 December 2011.

Webber, C. A., Roberson, J. A., McWhinney, M. C., Brown, R. E., Pinckard, M. J., \& Busch, J. F. (2005). After-hours power status of office equipment in the USA. http://escholarship.org/uc/item/4kd219h3. Accessed 6 December 2011.

Yung-Hsiang, L., \& De Micheli, G. (2001). Comparing systemlevel power management policies. IEEE Design \& Test of Computers, 18(2), 10-19. 